\title{
Modern vision on the problem of urolithiasis in children: epidemiology, etiopathogenesis, clinical, diagnostics, treatment, metaphylaxis
}

\author{
Assel Sagymbayeva ${ }^{1,2}$ \\ ${ }^{1}$ Department of Pediatric Surgery, Asfendiyarov Kazakh National Medical University, Almaty, Kazakhstan \\ ${ }^{2}$ Pediatric Urology Department, Scientific Center of Pediatrics and Pediatric Surgery, Almaty, Kazakhstan
}

Received: 2021-07-11.

Accepted: 2021-11-09.

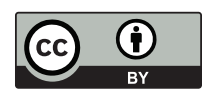

This work is licensed under a Creative Commons Attribution 4.0 International License

J Clin Med Kaz 2021; 18(6):9-14

Corresponding author:

Assel Sagymbayeva.

E-mail: sagymbaeva.assel@gmail.com;

ORCID: 0000-0001-6367-8327

\section{Abstract}

According to the study literature, urolithiasis remains one of the most common nosologies among the child population. In connection with the global changes in the health status of the population of our planet, the social significance of urolithiasis has recently acquired new relevance. The mechanism of stone formation is a complex process; stones are formed as a result of urine saturation with oxalates, calcium, uric acid, cystine. Most stones in children are located in the upper urinary tract. In 15\%-25\% of cases in children, urolithiasis may be asymptomatic. Diagnostics today are not difficult. If urolithiasis is suspected, first, among the instrumental research methods, ultrasound examination of the urinary tract is used, which identifies both X-ray-positive and X-raynegative stones. Nowadays, not all standards for treating obstructing stones of the upper urinary tract in children of various sizes and localizations, as well as the type of pelvis structure, have been defined. Simultaneously, new trends in treatment may change already existing standards. It should be noted that in the modern world and ways of metaphylaxis urolithiasis in children studied insufficiently. In the world literature, there is insufficient information on predicting the occurrence of recurrence of urolithiasis and ways to eliminate them. This literature review examines the epidemiology, etiopathogenesis of urolithiasis, diagnosis, existing treatment standards and metaphylaxis. Methods of active tactics of treatment of obstructive stones of the upper urinary tract are analysed in more detail.

Key words: urolithiasis in children, etiopathogenesis, kidney stones, prevalence, diagnosis, treatment, metaphylaxis

\section{Introduction}

Urolithiasis of the upper and lower urinary tract is a widespread disease, despite the fact that this pathology has been known since ancient times (in 1901, the archaeologist Smith found a bladder stone near the Egyptian village of El Amrah in a mummy buried 7000 years ago). Currently, urolithiasis is called a disease of civilization, since the factors that contribute to the increase in growth include modern living conditions, such as physical inactivity, leading to metabolic disorders, unbalanced nutrition. The prevalence of urolithiasis in some countries has increased by more than 7 times over the past century (Apolikhin O.I., 2017). It should be noted that an increase in the incidence of urolithiasis is noted in all age groups. According to the results of a comprehensive epidemiological study by Romero in 2010, the incidence of urolithiasis over the past 20 years in economically developed countries such as the USA, Germany, Italy, Spain and Japan has doubled, with a progressive increase in this indicator in those years. [1]. In our country, according to Alchinbaev M.K. (2016) among the adult population, there is an increase in the incidence of urolithiasis in the region from 42.3 per 100 thousand of the adult population in 2000 to 76.6 per 100 thousand of 
the population in 2015 [2]. It should be noted that when studying scientific publications over the past 20 years, there are no data on the frequency of urolithiasis in children in our country. In Russia, the incidence of urolithiasis in children is 19-20 cases, and in adolescents it reaches 80-90 cases per 100 thousand of the child population (Alyaev Yu.G., 2004). Other authors, such as Straub M., Gschwend J., Zorn C. (2010), also note an increase in the incidence of the disease in those periods, especially in children under the age of 1 year $[3,4]$.

According to the information of the National Health and Nutrition Examination Survey (NHANES), which helps analyze trends in the prevalence of kidney stones in the United States, shows that the prevalence increased from 5.2\% between 1988 1994 to $8.8 \%$ between 2007-2010 [5]. Thus, urolithiasis is a widespread disease, which tends to increase from year to year.

Despite the fact that urolithiasis has been studied for a long time, today there are no exact comprehensive unified scientific points of view about the etiopathogenesis of this pathology.

Exogenous and endogenous factors contribute to the stone formation. Exogenous factors include environmental and climatic conditions of the environment (air humidity, temperature fluctuations, precipitation and the influence of insolation), peculiarities of the chemical composition of soil and water, nutrition, social factors (physical inactivity).

Endogenous causes include genetically determined hereditary factors, endocrine disorders (hyperparathyroidism), diseases of the digestive tract (malabsorption syndrome, Crohn's disease), abnormalities of the urinary system, urinary infections.

There are many theories explaining the causes and mechanisms of pathogenic stone formation. The main ones are: microbial theory (Meckel, 1856); physical and chemical theory (Ultsman, 1890); the theory of colloid-crystalline equilibrium (Lichwitz and Schade, 1889); Matrix Theory (Randal, 1936). It is worth noting that all theories of stone formation are united by the main condition - the presence of urine supersaturation with stone-forming substances (minerals) and indicators, more precisely, the stability of the urine reaction $(\mathrm{pH})$.

It is known that the stone formation initially begins in the renal collecting system, terminal collecting ducts, or attached to the renal papillary surface or epithelial surface of the terminal collecting ducts [6].

In 1937, Randall suggested that kidney stone formation "requires an initial injury that precedes kidney stone formation" [7]. He reported that $17 \%$ of the 429 pairs of kidneys examined at autopsy had "calcium deposits on the walls and intertubular spaces of the renal papilla". He also described these plaques as the "natural process of repairing a type of tubular injury". After dissecting 1,154 pairs of kidneys, Randall found that $19.6 \%$ showed signs of calcified lesions in at least one renal papilla and 65 kidneys had a primary kidney stone attached to the papillary plaque $[8,9]$. He hypothesized that interstitial calcium phosphate $(\mathrm{CaP})$ and calcium carbonate deposits break out on the renal papilla surface and form a type I precalculus lesion [8], now known as Randall's plaques [10]. He also suggested that excessive urinary supersaturation, or "hypersecretion", leads to salt crystallization of stone formation and clogging of the collecting ducts, creating a type II precalculus lesion [9], now known as Randall's plaque [11]. Thus, Randall proposed two pathways for the formation of kidney stones. The first is through changes in the renal parenchyma and the formation of Randall's plaques, and the other, requiring changes in urine composition or supersaturation, leading to the development of Randall's plaques.
Khan et al. performed detailed scanning (SEM) and transmission electron microscopy (TEM) analysis of RPL and renal papillary tissue at the calculus attachment site. The plaque looked like a small ledge. SEM analysis showed that plaques were aggregates of spherical $\mathrm{CaP}$ crystals mixed with fibers of various thicknesses and other cellular products [12].

Sidorenko S.V. (2001) indicates the infectious genesis of stone formation in his work. Solkh R.M., Andryukhin M.I., Makarov O.V., Fedchenkov V.V. (2017) studied pathogenic urease-producing bacterial strains, in particular intestinal strains [13]. The cascade of reactions in the interaction of uropathogenic microorganisms and urothelium cells leads to disruption of the assembly of new villi and the expression of E. coli virulence genes [14-17].

In their works, the authors Carla G. Monico, Dawn S. Milliner (2011) describes the genetic determinants of urolithiasis, in particular idiopathic (polygenic and monogenic) forms of urolithiasis, which are caused by various disorders in the gene locus. For the common polygenic form of urolithiasis, studies of familial relationships and candidate genes have revealed abnormalities in calcium metabolism. It should be noted that monogenic forms of urolithiasis are mainly found in children and adolescents [18].

In few previous studies, $50-60 \%$ of cases of urolithiasis are inherited predisposition; the probability of developing in patients of the first-degree relatives and more distant family members has been estimated at $15 \%$ to $65 \%$, while $5-20 \%$ has relatives being affected by this disease [19]. In $65 \%$ of patients with calcium nephrolithiasis and in $70 \%$ with hypercalciuria may have a family history of the disorder [20]. More than 80 monogenic forms of urolithiasis are known, for example, xanthinuria, primary hyperoxaluria, cystinuria types A, B and $\mathrm{AB}$, metabolic disorders of 2,8-dihydroxyadenine, LeschNyhan syndrome and others [19, 21]. However, the main form of urolithiasis represented by polygenic inheritance [22].

Urolithiasis can be classified according to location, size, aetiology of formation, composition, and risk of recurrence. According to the European Association of Urology guidelines for urolithiasis, upper urinary tract stones can be classified according to size, as $\leq 5 \mathrm{~mm}, 5-10 \mathrm{~mm}, 10-20 \mathrm{~mm}$, and $>20 \mathrm{~mm}$ [19]. Stones can be classified according to anatomical position: in the calyx (upper, middle, lower), renal pelvis, ureter (proximal, middle, and distal) and urinary bladder. The composition and density of urinary stones can be assessed using native-computed tomography, which determines the X-ray density of stones in Hounsfield units. Based on the results of determining the density of stones, they are divided into 4 groups: 1) the density of stones is up to 500 units. $\mathrm{H}$; 2) the density of stones is from 501 to 1000 units. $\mathrm{H} ; 3$ ) the density of stones is from 1001 to 1500 units. $\mathrm{H}$; 4) the density of stones is over 1500 units. $\mathrm{H}$.

It should also be noted that according to the radiological characteristics, the stones are divided into radiopaque ones: calcium oxalate dihydrate, calcium oxalate monohydrate, calcium phosphate; low-contrast: magnesium and ammonium phosphate, apatite, cystine; non-contrast: uric acid, ammonium urate, xanthine, 2,8-dihydroxyadenine, medicinal stones (Table 1).

\section{By chemical composition:}

- Inorganic: calcium oxalate, calcium phosphate, ammonium magnesium, calcium carbonate.

- Organic: uric acid, ammonium urate, protein calculi: cystine, xanthine, 2,8-dihydroxyadenine. [23]

About $80 \%$ of urinary stones are calcium, most of which are calcium oxalate [24]. 


\begin{tabular}{|c|c|c|c|c|}
\hline Composition & $\begin{array}{l}\text { Frequency of the } \\
\text { occurrence }\end{array}$ & Radiological characteristics & $\begin{array}{l}\text { CT appearance (X-ray } \\
\text { density of stones) in } \\
\text { Hounsfield units (H) }\end{array}$ & Aetiological Factors \\
\hline $\begin{array}{l}\text { Calcium oxalate } \\
\text { monohydrate/dihydrate }\end{array}$ & $40-80 \%$ & Radiopaque & $1700-2800 \mathrm{H}$ & $\begin{array}{l}\text { Metabolic disorders } \\
\text { (idiopathic hypercalciuria or } \\
\text { hyperoxaluria) }\end{array}$ \\
\hline $\begin{array}{l}\text { Hydroxyapatite (calcium } \\
\text { phosphate) }\end{array}$ & $20-60 \%$ & Radiopaque & $1200-1800 \mathrm{H}$ & No metabolic abnormality \\
\hline & $2-4 \%$ & Radiopaque & $1700-2800 \mathrm{H}$ & $\begin{array}{l}\text { Not associated with } \\
\text { urinary tract infection }\end{array}$ \\
\hline Uric acid & $5-10 \%$ & Non-contrast & $200-450 \mathrm{H}$ & Idiopathic hyperuricemia \\
\hline Struvite & $5-15 \%$ & Radiopaque & $600-900 \mathrm{H}$ & Renal infection \\
\hline Cystine & $1-2,5 \%$ & Low-contrast & $600-1100 \mathrm{H}$ & Renal tubular defect \\
\hline
\end{tabular}

\section{Clinical manifestations}

The most common manifestations of urolithiasis in children are abdominal pain, dysuria, vomiting, oliguria, haematuria, pyuria, and urinary tract infections. Macroscopic or microscopic haematuria can be found in $90 \%$ of children with urolithiasis.

In a series of studies by Bayen M., Hamdi L., Hamdi A. et al. (2017), urinary tract infection and abdominal pain were the main clinical signs of urolithiasis in children. Most children with urolithiasis have a positive family history. $29.5 \%$ of patients had a family history of urolithiasis, which was an important factor in the etiological study and diagnosis of urolithiasis [25].

In $15-25 \%$ of cases in children, urolithiasis may be asymptomatic, which requires more attention [26]. It should be noted that, in infants, general symptoms of urolithiasis prevail, such as vomiting, nausea, abdominal pain without clear localization, while in school-age children, pain can be characterized as attack of acute pain in the form of renal colic. According to the study literature, approximately $80 \%$ of urinary tract calculi can be excreted spontaneously [27].
Pyuria is an almost constant symptom of urolithiasis. A pathological sign of urolithiasis is the excretion of stones in the urine. Spontaneous discharge of stones has observed in $51.21 \%$ of children [25]. The diameter of these stones is usually 4-5 $\mathrm{mm}$; however, in children, stones with a diameter of 9-10 mm may be discharged spontaneously, which is related to the greater elasticity of the urinary tract [4].

\section{Diagnostics}

With the introduction of modern ultrasound devices, X-ray research methods, at present, the diagnosis of urolithiasis does not cause any difficulties.

The simplest, non-invasive, readily available method for diagnosing urolithiasis is ultrasound (ultrasound). B-mode ultrasonography can detect stones in the kidney, in the proximal ureter at about the height of the inferior pole of the kidney, and in the distal ureter. As a rule, stones in other segments of the ureter cannot be visualized due to intestinal gas. The expansion 
of the calyx-pelvis system is an indirect sign of a kidney stone. The sensitivity and specificity of ultrasound diagnostics of nephrolithiasis is approximately $61-93 \%$ and $95-100 \%$, respectively. The accuracy of ultrasound examination for urolithiasis in children is also different. Stones could be found in $33-100 \%$ of cases. The information content of detecting stones by ultrasound is much higher in the kidneys than in comparison with the ureter [28].

Intravenous urography can reveal radiopaque stones. This method allows you to assess the excretory and evacuation function of the kidneys. According to the study literature, the specificity of urography is $82 \%$, and the sensitivity is $69 \%$ [29]. With obstructing stones of the upper urinary tract, an increase in the renal cavity system (calyx, pelvis) is noted, manifests itself in the form of secondary hydronephrosis.

Non-contrast computed tomography (NCT) is a method with the highest sensitivity of $91-100 \%$, corresponding to specificity (95-100\%, respectively) for examining ureteral stone. Using thin sections $(<5 \mathrm{~mm})$ to detect small stones. Noncontrast CT is superior to all other imaging techniques [30,31]. The measurement of density (Hounsfield unit) also facilitates the assessment of stone composition, which is important for treating urolithiasis [32].

However, the radiation dose in non-contrast computed tomography is about $2.8-5.0 \mathrm{mSv}$ [33], which is significantly higher than with traditional radiological methods. Because children with urinary stones are at a high risk of recurrence in their lifetime, they are likely to need multiple stone examinations over the course of their lives. Therefore, radiation exposure is an important issue in pediatric urology. Kuhns et al. calculated that the ratio of the risk of abdominal and pelvic cancer due to a single tubing for stones to the risk of natural cancer during the child's life is from $2 / 1000$ to $3 / 1000$ [34].

During the last decade, examination protocols with lower doses of radiation (the so-called ultra-low dose tubing) have been developed. However, this term is not standardized. Using these protocols, the radiation dose can be reduced to about $1-2.2 \mathrm{mSv}[35,36]$. However, the informative value decreases, especially with regard to the composition of the stone (measured in Hounsfield units), which jeopardizes the effectiveness of the treatment.

In addition, computed tomography makes it possible to assess the condition of the renal parenchyma, the presence of anomalies of the urinary system, more accurate localization of the stone, the density and volume of the calculus, which is an important step in planning treatment.

The laboratory methods for the study of urolithiasis include, in addition to a general blood test, a cogaulogram, a general urine analysis, the following methods are included: urine pH-metry, urine sediment study for leukocytes, erythrocytes, salts and bacteria; creatinine clearance; bacteriological culture of urine.

A complex of biochemical studies makes it possible to determine compounds such as calcium, phosphorus, magnesium and uric acid in blood serum and daily urine. In the scientific literature, a number of specialists indicate the advisability of determining oxalates and amino acids (cystine) in urine [37, 38]. X-ray crystallography or infrared spectroscopy; electron microscopy is currently used to study the chemical composition of a stone. These methods have both advantages and disadvantages. The advantages of infra-red spectroscopy are the speed of obtaining spectra of sufficient specificity, while using the minimum amount of the investigated material.

The combination of infrared spectroscopy and X-ray examination makes it possible to perform not only the qualitative, as well as the quantitative composition of the samples, determining the structure of the urinary calculus and the quantitative proportions of the constituent elements.

\section{Treatment}

Stone healing is mentioned in ancient Egyptian medical scriptures from $1500 \mathrm{BC}$. The first urinary stones were found in Egyptian mummies 4000-5000 BC. Between the 5th and the 3rd centuries $\mathrm{BC}$, doctors vowed to refrain from operations with stones, since the Hippocratic Oath states: "I will not use a knife even for patients with stones, but I will give it up in favour of those involved in this work." In the Middle Ages stone removal operations were performed by surgeons called lithotomists. For 500 years lithotomists travelled around Europe with their stonecut "lithotomy tables." In 1561, Pierre Franco performed the first suprapubic lithotomy to remove a stone in the bladder.

Advances in the treatment of urolithiasis in children were revolutionary with the development of shock wave lithotripsy in the early 1980 s, making it the treatment of choice for most upper urinary tract stones. Although recent advances in the improvement and modification of modern endoscopic equipment and techniques, treatment options and subsequent access to the urinary system have expanded. Extracorporeal shock wave lithotripsy is indicated for children without anomalies of the urinary tract and musculoskeletal system, with a stone size of up to $1 \mathrm{~cm}$. Although there is data in the literature where ESWL was used for stones measuring 1.5-2 cm, this approach should take into account repeated ESWL sessions to achieve complete extraction of stones "stone-free rates" [39-42]. Some studies report that the frequency of complete stone clearance for isolated stones in the lower calyx group varies from $50 \%$ to $62 \%$ [43-45]. For large and coral stones, as well as for stones in the lower calyx group, the use of ESWL is limited.

In 1929 Young was the first to report ureteroscopy. Since then, methods have been developed to avoid open surgical procedures and the need for "faceting".

Surgical methods of treatment are used for obstructing stones of the upper urinary tract. Over the past 20 years, a major breakthrough has been made in pediatric urology in the treatment of urolithiasis in favor of the use of endoscopic treatments such as ureteroscopy, intrarenal retrograde surgery, and transurethral ureteroscopic lithotripsy/lithoextraction.

Recent literature reported, in the last decades, percutaneous nephrolithotripsy (PNL) is used by urologists with stones more than $2 \mathrm{~cm}$, coral, large stones. The effectiveness of treatment when using PNL in children, according to various authors, was $50-98 \%[46,47]$

PNL is the treatment of choice for kidney stones $>2 \mathrm{~cm}$ $[46,47]$ and for cystine and whewellite stones [47]. Due to the miniaturization of instruments (so-called mini-, micro-, ultramini-PNL), indications have also expanded to include smaller kidney stones (10-20 mm) and lower calyx stones (> $10 \mathrm{~mm})$ [48].

Over the past 20 years, open surgical interventions in developed countries have been used in exceptional cases, such as unsuccessful repeated endoscopic methods for removing stones, anomalies of the urinary tract, and strictures of the ureter.

Urologic Diseases of America, funded by the National Institute of Diabetes and Digestive and Kidney Diseases (NIDDK), estimated the annual cost of kidney stones at \$10 billion in 2012, making it the most costly urological disease. 


\section{Metaphylaxis}

Special attention should be paid to the prevention of recurrence of urolithiasis. In particular, to infectious stones, so according to Iqbal M., 2013, the recurrence rate for these groups of stones reaches $15 \%$. The risk of recurrence of kidney stones after treatment of infectious stones reaches 100\% (Johri N., 2010; El-Nahas A., 2012). Which is explained as follows: bacteria can stay in kidney stones for a long time in the biofilm after crushing; the remaining small residual fragments form the nucleus of the stone, a new center of stone formation, which serves as a matrix for precipitating salts. The concept of metaphylaxis includes a complex of dietary, phytotreatic, medicinal, general health measures aimed at preventing the occurrence of recurrent stones. Metaphylaxis should start with general measures such as adequate fluid intake, balanced nutrition, treatment of concomitant diseases, phyto-prevention, and normalization of work and rest.

Metaphylaxis may primarily involve regulating fluid intake and diet. Increased fluid intake increases the volume of urine and prevents oversaturation and crystallization of crystals. In children, the fluid intake required for adequate diuresis should be calculated per $1.5 \mathrm{~L} / \mathrm{m} 2$ body area. Sugary drinks should be avoided as liquids containing glucose and fructose increase the excretion of calcium and oxalate. In addition, fluid intake should be spread throughout the day. Therefore, in stone metaphylaxis, water intake is the approach that has the best cost-benefit ratio [49]. However, it is impossible to control children's fluid intake at school and in general, children do not adhere well to the rules of hydration. Because fluid requirements depend on temperature and activity level, parents may be advised to monitor hydration based on urine color and density, if possible. The density of urine, many times higher than 1010, indicates insufficient fluid intake [50].

\section{Conclusion}

Despite the fact that the problem of urolithiasis has been studied for centuries, many questions remain open, in particular etiopathogenesis, the rapid progressive development of urolithiasis in children and metaphylaxis. If we talk about the diagnosis of urolithiasis, clinical signs in children can be erased, however, changes in urine tests should alert the clinician, send a child suspected of urinary tract pathology for an ultrasound examination, which allows to identify stones, both X-ray positive and X-ray-negative calculi. For obturation stones of the upper urinary tract, according to this literature review, percutaneous lithotripsy is the first-line surgical treatment. In the last decade, endoscopic devices have been improved, instruments have been minimized, which makes it possible to use this method for removing stones in all age groups of children. Every year, the number of morbidity and prevalence of this pathology is increasing, which entails large financial costs. In modern urology, much attention is paid to minimally invasive methods of treatment; unfortunately, there are little data on metaphylaxis in the world literature. According to the study literature, there is information about general measures for preventing recurrence of stone formation. Urolithiasis is a multifactorial, polyetiologic disease, therefore, in the management of this pathology, the approach should be multidisciplinary, patient management should be individual.

Disclosures: There is no conflict of interest.

Acknowledgements: None.

Funding: None.

\section{References}

1. Romero V, Akpinar H, Assimos DG. Kidney stones: a global picture of prevalence, incidence, and associated risk factors. Rev Urol. 2010;12(2-3): 86-96.

2. Alchinbaev MK, Urolithiasis in Kazakhstan. Analysis of the situation and prospects [in Russian]. Urology and Nephrology of Kazakhstan. 2016; 2; 9-21.

3. Akimoto M, Higashihara E, Kumon H, Masaki Z, Orikasa S. Treatment of Urolithiasis. Germany: Springer-Verlag; 2001.126 p.

4. Straub M, Gschwend J, Zorn C. Pediatric urolithiasis: the current surgical management. Pediatr Nephrol. 2010;25(7):1239-44. https:// doi: 10.1007/s00467-009-1394-4.

5. Sorokin I, Mamoulakis, K. Miyazawa, A. Rodgers, J. Talati, Y. Lotan Epidemiology of stone disease across the world. World J. Urol. 2017. 35 (9):1301-1320. https://doi: 10.1007/s00345-017-2008-6

6. Khan SR, Pearle MS, Robertson WG, Gambaro G, Canales BK, Doizi S, Traxer O, Tiselius HG. Kidney stones. Nat Rev Dis Primers. 2016; 2:16008. https://doi: 10.1038/nrdp.2016.8.

7. Randall A. The origin and growth of renal calculi. Ann Surg. 1937; 105(6):1009-27. https://doi: 10.1097/00000658-193706000-00014.

8. Randall A. Papillary pathology as a precursor of primary renal calculus. Journal of Urology. 1940; 44:580. https://doi.org/10.1016/ S0022-5347(17)71305-5

9. Randall A. The etiology of primary renal calculus. International Abstract of Surgery. 1940; 71:209.

10. Stoller ML, Low RK, Shami GS, McCormick VD, Kerschmann RL. High resolution radiography of cadaveric kidneys: unraveling the mystery of Randall's plaque formation. J Urol. 1996;156(4):1263-6. https://doi: 10.1016/s0022-5347(01)65565-4.

11. Khan SR, Canales BK. Unified theory on the pathogenesis of Randall's plaques and plugs. Urolithiasis. $2015 ; 43$ Suppl 1(01):109-23. https://doi: 10.1007/s00240-014-0705-9.

12. Khan SR, Rodriguez DE, Gower LB, Monga M. Association of Randall plaque with collagen fibers and membrane vesicles. $J$ Urol. $2012 ; 187(3): 1094-100$. doi: 10.1016/j.juro.2011.10.125.

13. Solkh RM, Andryukhin MI, Makarov OV, Fedchenkov VV Improvement of treatment results in patients with ureteral calculi after contact ureterolithotripsy. Research and practice in medicine [in Russian]. 2017; 2:8-12.

14. Seregin AV, Mulabaev NS, Tolordava ER. Modern aspects of the etiopathogenesis of urolithiasis [in Russian]. Medicine. 2012; 4:4-10.

15. Pasupuleti S, Sule N, Manson MD, Jayaraman A. Conversion of Norepinephrine to 3,4-Dihdroxymandelic Acid in Escherichia coli Requires the QseBC Quorum-Sensing System and the FeaR Transcription Factor. J Bacteriol. 2017; 200(1):e00564-17. https://doi: 10.1128/JB.00564-17.

16. Tao Y, Pinzón-Arango PA, Howell AB, Camesano TA. Oral consumption of cranberry juice cocktail inhibits molecular-scale adhesion of clinical uropathogenic Escherichia coli. J Med Food. 2011; 14(7-8):739-45. https://doi: 10.1089/jmf.2010.0154.

17. David G. Thanassi, James B. Bliska, Peter J. Christie, Surface organelles assembled by secretion systems of Gram-negative bacteria: diversity in structure and function, FEMS Microbiology Reviews. 2012; 36(6):1046-1082. https://doi.org/10.1111/j.15746976.2012.00342.x 
18. Monico CG, MillinerDS. Genetic determinants of urolithiasis. Nat Rev Nephrol. 2011; 8(3):151-62.https://doi: 10.1038/nrneph.2011.211.

19. Turk C, Neisius A, Petrik A, et al. EAU Guidelines on urolithiasis. European Association of Urology. 2021; 87

20. Maltsev S.V., Mikhailova T.V. Genetic and clinical aspects of nephrolithiasis and nephrocalcinosis in children with hypercalciuria [in Russian]. Pediatrics 2014; 9 (85): 118-25.

21. Filippova T.V. Rudenko V.I. Genetic aspects of primary hyperoxaluria: epidemiology, aetiology, pathogenesis and clinical manifestations [in Russian]. Bulletin of the Russian Society of Urology. 2019; (3): 24-5

22. Svetlichnaya D. V. Litvinova M. M. Molecular genetic panel in the assessment of susceptibility to urolithiasis. [in Russian] Materials of the Congress. XIX Congress of the Russian Society of Urology (September 19-21, Rostov-on-Don) 2019; from. 195

23. Kambadakone AR, Eisner BH, Catalano OA, Sahani DV. New and evolving concepts in the imaging and management of urolithiasis: urologists' perspective. Radiographics. 2010;30(3):603-23. https://doi: 10.1148/rg.303095146.

24. Alelign T, Petros B. Kidney stone disease: an update on current concepts. Adv Urol. 2018;2018:1-12. https://doi:10.1155/2018/3068365

25. Maalej B, Louati H, Abid H, Zitouni H, Weli M, et al. Pediatric Urolithiasis in Children: Diagnosis and Management. Med Sur Urol . 2017; 6: 196. https://doi:10.4172/2168-9857.1000196

26. VanDervoort K, Wiesen J, Frank R, Vento S, Crosby V, Chandra M, Trachtman H. Urolithiasis in pediatric patients: a single center study of incidence, clinical presentation and outcome. J Urol. 2007;177(6):2300-5. https://doi: 10.1016/j.juro.2007.02.002.

27. Dincel N, Resorlu B, Unsal A, et al. Are small residual stone fragments really insignificant in children? J Pediatr Surg. 2013;48:840-4. https://doi:10.5505/kjms.2015.80388

28. Strohmaier, Walter Ludwig. Imaging in pediatric urolithiasis-what's the best choice? Translational pediatrics. 2015; 4(1):36-40. https:// doi:10.3978/j.issn.2224-4336.2015.01.01

29. Eray O, Cubuk MS, Oktay C, Yilmaz S, Cete Y, Ersoy FF. The efficacy of urinalysis, plain films, and spiral CT in ED patients with suspected renal colic. Am J Emerg Med. 2003; 21(2):152-4. https://doi: 10.1053/ajem.2003.50027.

30. Pfister SA, Deckart A, Laschke S, Dellas S, Otto U, Buitrago C, Roth J, Wiesner W, Bongartz G, Gasser TC. Unenhanced helical computed tomography vs intravenous urography in patients with acute flank pain: accuracy and economic impact in a randomized prospective trial. Eur Radiol. 2003; 13(11):2513-20. https://doi: 10.1007/s00330-003-1937-1.

31. Yilmaz S, Sindel T, Arslan G, Ozkaynak C, Karaali K, Kabaalioğlu A, Lüleci E. Renal colic: comparison of spiral CT, US and IVU in the detection of ureteral calculi. Eur Radiol. 1998;8(2):212-7. https://doi: 10.1007/s003300050364.

32. Sheir KZ, Mansour O, Madbouly K, Elsobky E, Abdel-Khalek M. Determination of the chemical composition of urinary calculi by noncontrast spiral computerized tomography. Urol Res. 2005;33(2):99-104. https://doi: 10.1007/s00240-004-0454-2.

33. Chateil JF, Rouby C, Brun M, Labessan C, Diard F. Mesure pratique de l'irradiation en radiopédiatrie: utilisation du produit dose surface en fluorographie numérique et pour les radiographies pulmonaires néonatales [Practical measurement of radiation dose in pediatric radiology: use of the dose surface product in digital fluoroscopy and for neonatal chest radiographs]. J Radiol. 2004;85(5 Pt 1):619-25. French. https://doi: 10.1016/s0221-0363(04)97638-x.

34. Kuhns LR, Oliver WJ, Christodoulou E, Goodsitt MM. The predicted increased cancer risk associated with a single computed tomography examination for calculus detection in pediatric patients compared with the natural cancer incidence. Pediatr Emerg Care. 2011;27(4):345-50. https://doi: 10.1097/PEC.0b013e3182132016.

35. Liu W, Esler SJ, Kenny BJ, Goh RH, Rainbow AJ, Stevenson GW. Low-dose nonenhanced helical CT of renal colic: assessment of ureteric stone detection and measurement of effective dose equivalent. Radiology. 2000;215(1):51-4. https://doi: 10.1148/ radiology.215.1.r00ap4051.

36. Rogalla P, Klüner C, Taupitz M. Ultra-Niedrigdosis-CT zur Steinsuche in Nieren und ableitenden Harnwegen [Ultra-low-dose CT to search for stones in kidneys and collecting system]. Aktuelle Urol. 2004;35(4):307-9. German. https://doi: 10.1055/s-2004-830031.

37. Kolpakov IS.Urolithiasis: a guide for doctors. Moscow. Medical News Agency. 2014. 368 p.

38. Julka S, Gupta SK, Srivastava A. Protocol-based metabolic evaluation in high-risk patients with renal stones in North India. Indian J Endocrinol Metab. 2012;16(2):283-287. https://doi:10.4103/2230-8210.93754.

39. Ather MH, Noor MA. Does size and site matter for renal stones up to 30-mm in size in children treated by extracorporeal lithotripsy? Urology. 2003;61(1):212-215. https://doi: 10.1016/s0090-4295(02)02128-3.

40. Lottmann HB, Traxer O, Archambaud F, Mercier-Pageyral B. Monotherapy extracorporeal shock wave lithotripsy for the treatment of staghorn calculi in children. J Urol. 2001;165(6 Pt 2):2324-7. https://doi: 10.1097/00005392-200106001-00027. PMID: 11371942.

41. McAdams S, Shukla AR. Pediatric extracorporeal shock wave lithotripsy: Predicting successful outcomes. Indian J Urol. 2010; 26(4):544-548. https://doi:10.4103/0970-1591.74457

42. Tan AH, Al-Omar M, Watterson JD, Nott L, Denstedt JD, Razvi H. Results of shockwave lithotripsy for pediatric urolithiasis. J Endourol. 2004;18(6):527-30. https://doi: 10.1089/end.2004.18.527.

43. Demirkesen O, Onal B, Tansu N, Altintaş R, Yalçin V, Oner A. Efficacy of extracorporeal shock wave lithotripsy for isolated lower caliceal stones in children compared with stones in other renal locations. Urology. 2006;67(1):170-4; discussion 174-5. https://doi: 10.1016/j.urology.2005.07.061.

44. Onal B, Demirkesen O, Tansu N, Kalkan M, Altintaş R, Yalçin V. The impact of caliceal pelvic anatomy on stone clearance after shock wave lithotripsy for pediatric lower pole stones. J Urol. 2004;172(3):1082-6. https://doi: 10.1097/01.ju.0000135670.83076.5c.

45. Ozgür Tan M, Karaoğlan U, Sen I, Deniz N, Bozkirli I. The impact of radiological anatomy in clearance of lower calyceal stones after shock wave lithotripsy in paediatric patients. Eur Urol. 2003;43(2):188-93. https://doi: 10.1016/s0302-2838(02)00492-x.

46. Hwang K, Mason MD, Peters CA. Clinical practice: surgical approaches to urolithiasis in children. Eur J Pediatr. 2011;170(6):681-8. https://doi: 10.1007/s00431-010-1373-6.

47. Smaldone MC, Docimo SG, Ost MC. Contemporary surgical management of pediatric urolithiasis. Urol Clin North Am. 2010;37(2):25367. https://doi: 10.1016/j.ucl.2010.03.006.

48. Salah MA, Toth C, Khan AM, Holman E. Percutaneous nephrolithotomy in children: experience with 138 cases in a developing country. World J Urol. 2004;22(4):277-280. https://doi: 10.1007/s00345-004-0454-4.

49. Lotan Y, Buendia Jiménez I, Lenoir $\square$ Wijnkoop I, Daudon M, Molinier L, Tack I, Nuijten MJ. Increased water intake as a prevention strategy for recurrent urolithiasis: Major impact of compliance on cost $\square$ effectiveness. Journal of Urology. 2013;189(3):935-939. https://doi: 10.1016/j.juro.2012.08.254

50. Borghi L, Meschi T, Maggiore U, Prati B. Dietary therapy in idiopathic nephrolithiasis. Nutr Rev. 2006;64(7 Pt 1):301-12. https://doi: 10.1301/nr.2006.jul.301-312. 